\section{A) Check for updates}

Cite this: J. Mater. Chem. B, 2017, 5,3879

\title{
On the subtle tuneability of cellulose hydrogels: implications for binding of biomolecules demonstrated for CBM $1 \dagger$
}

\author{
M. A. Johns, (iD) ${ }^{a b}$ A. Bernardes, ${ }^{C}$ E. Ribeiro De Azevêdo, ${ }^{C}$ F. E. G. Guimarães, ${ }^{C}$ \\ J. P. Lowe, ${ }^{d}$ E. M. Gale, (D) $\ddagger^{\text {ad }}$ I. Polikarpov, ${ }^{c}$ J. L. Scott (D) ${ }^{\text {ad }}$ and R. I. Sharma*ab
}

\begin{abstract}
Cellulose-based hydrogel materials prepared by regeneration from cellulose solutions in ionic liquids, or ionic liquid containing solvent mixtures (organic electrolyte solutions), are becoming widely used in a range of applications from tissue scaffolds to membrane ionic diodes. In all such applications knowledge of the nature of the hydrogel with regards to porosity (pore size and tortuosity) and material structure and surface properties (crystallinity and hydrophobicity) is critical. Here we report significant changes in hydrogel properties, based on the choice of cellulose raw material ( $\alpha$ - or bacterial cellulose - with differing degree of polymerization) and regeneration solvent (methanol or water). Focus is on bioaffinity applications, but the findings have wide ramifications, including in biomedical applications and cellulose saccharification. Specifically, we report that the choice of cellulose and regeneration solvent influences the surface area accessible to a family 1 carbohydrate-binding module (CBM), CBM affinity for the cellulose material, and rate of migration through the hydrogel. By regenerating bacterial cellulose in water, a maximum accessible surface area of $33 \mathrm{~m}^{2} \mathrm{~g}^{-1}$ was achieved. However, the highest CBM migration rate, $1.76 \mu \mathrm{m}^{2} \mathrm{~min}^{-1}$, was attained by regenerating $\alpha$-cellulose in methanol, which also resulted in the maximum affinity of the biomolecule for the material. Thus, it is clear that if regenerated cellulose hydrogels are to be used as support materials in bioaffinity (or other) applications, a balance between accessible surface area and affinity, or migration rate, must be achieved.
\end{abstract}

Received 16th January 2017, Accepted 1st May 2017

DOI: $10.1039 / \mathrm{c} 7 \mathrm{tb} 00176 \mathrm{~b}$

rsc.li/materials-b

\section{Introduction}

Cellulose is well established as a raw material supply for environmentally friendly and biocompatible products, including property-determining additives for foods, cosmetics, coatings, and synthetic fibres. ${ }^{1}$ Recent applications include tissue scaffolds, ${ }^{2}$ biomimetic $4 \mathrm{D}$ printing, ${ }^{3}$ and membrane ionic diodes. ${ }^{4}$ A naturally occurring biopolymer, it is biocompatible and is viewed as being almost inexhaustible, with an estimated 28.2 billion tonnes produced via biomass each year. ${ }^{1,5}$ The use of ionic liquids to

\footnotetext{
${ }^{a}$ Centre for Sustainable Chemical Technologies, University of Bath, BA2 7AY, UK. E-mail: j.l.scott@bath.ac.uk, r.sharma@bath.ac.uk

${ }^{b}$ Department of Chemical Engineering, University of Bath, BA2 7AY, UK

${ }^{c}$ São Carlos Institute of Physics, University of São Paulo, 13566-590, Brazil

${ }^{d}$ Department of Chemistry, University of Bath, BA2 7AY, UK

$\dagger$ Electronic supplementary information (ESI) available: Methylene blue HPLC calibration curve, $C$ versus $C / N$ plots for methylene blue and $T h$ CBM1 $_{\text {СвHI }}$ adsorption isotherms, $N_{\mathrm{m}}$ and $K$ values for methylene blue and $T h \mathrm{CBM} 1_{\mathrm{CBHI}}$ adsorption isotherms, bleaching images demonstrating fluorescent recovery. See DOI: $10.1039 / \mathrm{c} 7 \mathrm{tb} 00176 \mathrm{~b}$

\# Current address: School of Experimental Psychology, University of Bristol, BS8 1TH, UK.
}

dissolve cellulose, followed by regeneration with an anti-solvent, has enabled the development of cellulose-based materials of variable forms, including hydrogels. ${ }^{6-8}$ More recently, Rinaldi demonstrated that the instantaneous dissolution of cellulose at room temperature is made possible by combining the ionic liquid with a dipolar aprotic co-solvent. ${ }^{9}$ It has been demonstrated that the choice of anti-solvent, used to regenerate cellulose from an ionic liquid solution can influence the material properties of the resultant hydrogel. For example, it has been reported that less crystalline materials result when alcohol anti-solvents are applied compared with water ${ }^{10}$ and that enhanced enzymatic hydrolysis is observed for cellulose regenerated in alcohol. ${ }^{11}$

Carbohydrate-binding modules (CBMs) are protein domains found in cellulose-degrading enzymes that are responsible for guiding the appended catalytic domain of the enzyme to the cellulose surface. ${ }^{12}$ They can be independently expressed via recombinant plasmid cloning, ${ }^{13}$ enabling their use in bioaffinity attachment without modification, or grafting, of the cellulose substrate. Bioaffinity attachment is of particular interest as it ensures controlled orientation of the active molecule, resulting in improved activity, and is generally reversible despite the attached agent being strongly bound. ${ }^{14}$ This enables the production of 
novel biocatalysts and biosorbents with enhanced performance; ${ }^{15-18}$ support matrices for affinity chromatography and biosensors; ${ }^{19-21}$ and biocompatible scaffolds for human tissue growth. ${ }^{22-24}$

Tomme et al. previously reported that CBMs belonging to family 1, such as CBM1 of cellobiohydrolase I from Trichoderma harzianum (ThCBM $\mathrm{CBHI}_{\mathrm{CB}}$ ), used in this work, reversibly bind to cellulose. ${ }^{25}$ This provides the opportunity to develop separation and purification applications, or regenerable biosensors, both of which require reversible binding of the active biomolecule. ${ }^{14}$ In order to assess whether cellulose hydrogels regenerated from ionic liquids are suitable supports for these applications, and to develop an understanding of their subsequent degradation rate, three parameters need to be investigated: (i) the accessible surface area of the hydrogel; (ii) the CBM partition constant; and (iii) the CBM diffusion rate.

It is desirable that the accessible surface area of the hydrogel is high, as this minimizes the mass of cellulose required for the application. It might also be expected to enable a higher rate of hydrolysis. In the same vein, a high CBM partition constant (a measurement that describes the affinity of the CBM for the material) is desirable in order to minimise excess CBM remaining in solution once the CBM has adsorbed onto the material. This is more important than the accessible surface area for bioaffinity applications given that cellulose is inexpensive compared to biomolecules, which require laborious expression, isolation and purification. Finally, a high CBM diffusion rate is desirable, as this will minimize the time required to load the hydrogel with the CBM and aid its subsequent removal. This is of importance at an industrial scale, as time is directly linked to cost.

It is known that family 1 CBMs preferentially bind to surfaces that are crystalline and hydrophobic. ${ }^{12,26,27}$ Therefore, we investigated hydrogels regenerated from an ionic liquid/ co-solvent mixture (organic electrolyte solution) comprised of 30: 70 1-ethyl-3-methyl imidazolium acetate: dimethyl sulfoxide ([EMIm][OAc]: DMSO) by weight using either methanol, or water, as the anti-solvent. Such materials are designated regenerated in methanol (rM), or regenerated in water (rW), respectively. The effect of the cellulose degree of polymerization (DP) on the resulting pore structure was evaluated using $\alpha$-cellulose (AC), DP: $500-1300,{ }^{28}$ and bacterial cellulose (BC), DP: $2000-6000 .^{29}$ Herein, we demonstrate that the crystallinity, hydrophobicity and tortuosity of the regenerated hydrogel is dependent on both the type of cellulose and the anti-solvent used to regenerate the hydrogel, which, in turn affects the affinity of the CBM for the material and also modulates the rate of CBM migration within the hydrogel.

\section{Experimental}

\section{Materials}

Glucose, yeast extract, peptone, anhydrous disodium phosphate, citric acid monohydrate, sodium hypochlorite, 1-ethyl-3-methylimidazolium acetate, dimethyl sulfoxide, methanol, methylene blue, trifluoroacetic acid, acetonitrile, kanamycin sulfate, chloramphenicol, isopropyl- $\beta$-D-thiogalactopyranoside, Trizma ${ }^{\circledR}$ base, 2-mercaptoethanol, glycerol, imidazole and $\alpha$-cellulose were purchased from Sigma Aldrich. Alexa Fluor 488 C5 Maleimide dye was purchased from Invitrogen.

\section{Bacterial cellulose production}

Cellulose-producing bacteria from an acetobacter containing culture§ were grown at $25{ }^{\circ} \mathrm{C}$ in Hestrin \& Schramm medium (distilled water supplemented with $2 \mathrm{wt} \%$ glucose, $0.5 \mathrm{wt} \%$ yeast extract, $0.5 \mathrm{wt} \%$ peptone, $0.27 \mathrm{wt} \%$ anhydrous disodium phosphate, and 0.15 wt $\%$ citric acid monohydrate). ${ }^{30}$ The resulting bacterial cellulose pellicle was treated with a solution of $10 \mathrm{wt} \%$ sodium hypochlorite for $1 \mathrm{~h}$ before being washed three times with copious amounts of distilled water and lyophilised using a mini lyotrap (LTE Scientific) freeze dryer.

\section{CBM mutagenesis, expression and purification}

The cellobiohydrolase I carbohydrate-binding module gene from Trichoderma harzianum (ThCBM $\left.1_{\mathrm{CBHI}}\right)$ was cloned as described by Mello \& Polikarpov: ${ }^{31}$ the CBM gene was cloned into a pSMT3 expression vector, which encodes a $6 \mathrm{His}-\mathrm{SUMO}$ $\mathrm{N}$-terminal tag. ${ }^{32}$ A CBM site direct-mutagenesis S19C was performed, introducing a free cysteine residue, to ensure efficient protein labelling with fluorescent probes. DNA single mutation was introduced using QuickChange II Site-Directed Mutagenesis Kit (Stratagene) as per the manufacturer's protocol. For this approach, PCR amplification of an entire plasmid was performed using primers with mutation $5^{\prime}$-TGCGCTTGCGG CTACACTTG-3' (forward) and 5'-TCTGGTAGGTCCGGTCCAG CC-3' (backward). The mutagenesis product was transformed into $E$. coli $\mathrm{DH} 5 \alpha$, and plasmid mini-preparations were used in the single colonies that grew in presence of kanamycin. The coding regions in the mutant plasmid were verified by DNA sequencing and then chemically transformed into E. coli Rosetta (DE3) strain for protein expression.

Transformed $E$. coli cells were cultured in LB broth containing kanamycin $\left(50 \mu \mathrm{g} \mathrm{mL}^{-1}\right)$ and chloramphenicol $\left(34 \mu \mathrm{g} \mathrm{mL}^{-1}\right)$ at $37{ }^{\circ} \mathrm{C}$. After the medium absorbance at $600 \mathrm{~nm}$ reached 0.8 , protein expression was induced with $1 \mathrm{mM}$ isopropyl- $\beta-\mathrm{D}^{-}$ thiogalactopyranoside and cells incubated for $16 \mathrm{~h}$ at $18{ }^{\circ} \mathrm{C}$. The cells were harvested by centrifugation and resuspended in buffer A (20 mM Tris pH 7.5, $300 \mathrm{mM} \mathrm{NaCl,} \mathrm{5 \%} \mathrm{glycerol,} 1 \mathrm{mM}$ phenylmethanesulfonylfluoride and $4.3 \mathrm{M}$ 2-mercaptoethanol). The sample was sonicated to disrupt the cells and centrifuged at $14000 \mathrm{rpm}$ for $40 \mathrm{~min}$. The soluble fraction of ThCBM1 $1_{\mathrm{CBHI}}+$ SUMO was submitted to $\mathrm{Ni}^{2+}$ affinity purification. Buffer A was used to wash the set proteins/resin and protein elution was achieved with an imidazole gradient through a gradual increase of buffer B (20 mM Tris pH 7.5, $150 \mathrm{mM} \mathrm{NaCl,} 300 \mathrm{mM}$

$\S$ While BC is often ascribed to production by a particular strain, it can be more productive to use mixed cultures, such as those used in production of the drink 'kombucha', followed by appropriate purification, particularly where the material is then dissolved so removing any structural features. Reva et al., have reported that the core of such communities are comprised of acetobacteria of two genera, Komagataeibacter (formerly Gluconacetobacter) and Gluconobacter. ${ }^{60}$ 
imidazole, 5\% glycerol, and 4.3 M 2-mercaptoethanol). All the eluted samples were analyzed by $15 \%$ (wt/wt) SDS-PAGE.

\section{Cellulose hydrogel generation}

Cellulose ( $4 \mathrm{wt} \%, \alpha$-, or bacterial) was dissolved in a solution of $30: 70 \mathrm{wt} \%$ [EMIm] [OAc]: DMSO at $25{ }^{\circ} \mathrm{C}$ overnight on a roller table in order to achieve complete dissolution. The solutions were then tape cast using an Elcometer 4340 Automatic Film Applicator with a distance of $500 \mu \mathrm{m}$ between the blade and glass surface. The resulting film was regenerated by immersion in the chosen anti-solvent for $20 \mathrm{~min}$ and washed twice with copious amounts of distilled water to remove excess solvent before being stored in a solution of $20 \mathrm{wt} \% \mathrm{MeOH}$ in water in order to inhibit bacterial growth.

\section{Powder X-ray diffraction (pXRD)}

Pieces of the cellulose hydrogels were frozen using liquid nitrogen and ground to powders using a pestle and mortar. These were analyzed using a flat plate BRUKER D8-Advance $\left(\mathrm{Cu} \mathrm{K} \mathrm{K}_{\alpha}, \lambda 1.5418 \AA\right.$ radiation) powder X-ray diffractometer over the $2 \theta$ range $4-60^{\circ}$ with a step size of $0.016^{\circ}$ and step time of $0.8 \mathrm{~s}$. The curve-fitting software, Fityk, was used to deconvolute the raw pXRD data: Gaussian curves were fitted to the signals in the amorphous and crystalline regions. ${ }^{33}$ The crystallinity index was calculated as the ratio between the sum of the crystalline peak areas and the total peak area.

\section{NMR cryoporometry}

The cellulose samples were soaked in water overnight, excess surface water removed, and the samples placed in individual NMR tubes and sealed using damp absorbent paper to maintain high humidity. The ${ }^{1} \mathrm{H}$ NMR signal was recorded on a $400 \mathrm{MHz}$ Bruker Avance spectrometer equipped with a $5 \mathrm{~mm}$ BBO probe, running with the boil-off from liquid nitrogen as cooling gas, and a BVT3200 temperature control unit with precision of $\pm 0.1 \mathrm{~K}$. Actual versus recorded temperatures had previously been calibrated using a methanol sample. ${ }^{34}$ A simple spin echo pulse sequence was used, with an echo time of $2.2 \mathrm{~ms}$, to ensure minimal suppression of signal from liquid water and complete suppression of signals from both cellulose and frozen water. ${ }^{35,36}$ Measurements were performed by decreasing the temperature to $218 \mathrm{~K}$ in order to completely freeze the sample, followed by increasing the temperature stepwise by $5 \mathrm{~K}$ up to $258 \mathrm{~K}$, then in $1 \mathrm{~K}$ steps to $267 \mathrm{~K}, 0.2 \mathrm{~K}$ steps to $271 \mathrm{~K}$, and finally to bulk melting temperature using a temperature step of $0.1 \mathrm{~K}$. At each increment signals were recorded after establishment of thermal equilibrium, achieved by a waiting time of $20 \mathrm{~min}$.

The melting point depression, $\Delta T$, is related to the pore radius, $r$, via the bulk properties of the probe liquid, $P$, as described by the Gibbs-Thomson equation:

$$
\Delta T \propto \frac{P}{(r-s)}
$$

where $P$ is $25 \mathrm{~nm}$ for water and $s$ represents the thickness of a pre-molten liquid-like layer on the surface of the substrate, here assumed constant over the temperature range and two monolayers thick, i.e. $0.6 \mathrm{~nm} .{ }^{10}$

\section{NMR relaxometry}

Transverse relaxation times, $T_{2}$, were measured via Carr-PurcellMeiboom-Gill (CPMG) echo train acquisition using a Bruker Minispec MQ-20 spectrometer operating with a magnetic field of $0.5 \mathrm{~T}\left({ }^{1} \mathrm{H}\right.$ Larmor frequency of $\left.20 \mathrm{MHz}\right)$ at $40{ }^{\circ} \mathrm{C} .10000$ Echoes were acquired with echo (relaxation delay) times $\left(t_{\mathrm{E}}\right)$ of $1 \mathrm{~ms}$ and total recycle delays of $15 \mathrm{~s}$. In fluids in the fast diffusion regime, there is a close relation between the $T_{2}$ values and the surface-tovolume ratio of pores. ${ }^{35,37}$ In this particular case, the magnetic field is not highly heterogeneous; there are no paramagnetic, or magnetic, impurities on the pore surface; and relatively short echo times were used. Under these conditions the relation between $T_{2}$ and the surface to volume ratio is:

$$
\frac{1}{T_{2}}=\left(\frac{1}{T_{2}}\right)_{\text {bulk }}+\rho_{2}\left(\frac{S}{V}\right)
$$

where $\rho_{2}$ is the relaxivity constant of the fluid in the pores of the material, and $S$ and $V$ are the pore surface area and volume respectively. As the relaxivity constant of the fluid used to fill the cellulose pores, i.e. water in PBS, is unknown, it is not possible to obtain the surface to volume ratio of the pores, but the trends of $T_{2}$ may be directly associated with variation in the sizes of regions filled with the solution. Larger $T_{2}$ values correspond to larger pores. $^{38}$

Besides the averaged $T_{2}$ values, the measurement of the decay of the CPMG echo train, CPMG decay $S_{\mathrm{CPMG}}(t), T_{2}$ distribution profiles, $g\left(T_{2}\right)$, associated with distribution of pore sizes and variations in the water mobility within the pores, can be obtained using a non-negative least square procedure also known as a numerical inverse Laplace transform (ILT) to fit the $S_{\mathrm{CPMG}}(t)$ curves. $^{39,40}$ In this case, an ILT method implemented in Matlab was used.

\section{Scanning electron microscopy}

Samples of the cellulose hydrogels were dried using a mini lyotrap (LTE Scientific) freeze dryer. The dense skin layer was peeled off with adhesive tape to reveal the core pore structure. Samples were sputter coated with gold for $5 \mathrm{~min}$ in an Edwards S150B sputter coater and specimens imaged with a JEOL SEM6480LV operating at $5 \mathrm{kV}$.

\section{Molecular probe adsorption}

Methylene blue (MB) depletion isotherms were constructed by incubating five $134.2 \mathrm{~mm}^{2}$ pieces of the cellulose hydrogels with various concentrations $(5-1000 \mu \mathrm{M})$ of $\mathrm{MB}$ in $5 \mathrm{~mL}$ of distilled water with $0.01 \mathrm{wt} \%$ trifluoroacetic acid. MB controls without cellulose were included and all experiments were carried out in triplicate. Samples were incubated at $4{ }^{\circ} \mathrm{C}$ for $24 \mathrm{~h}$, after which time the concentration of the bound MB was calculated from the difference in the original and final $\mathrm{MB}$ concentrations in the supernatant: $1 \mathrm{~mL}$ of the supernatant was removed and spectrophotometrically analysed in a 1260 Infinity Series (Agilent Technologies) HPLC (flow rate: $1 \mathrm{~mL} \mathrm{~min}^{-1}$, 
injection volume: $1 \mu \mathrm{L}$, absorbance wavelength: $660 \mathrm{~nm}$, column: Poroshell 120 EC-C18 $2.7 \mu \mathrm{m} 4.6 \times 50 \mathrm{~mm}$ (Agilent Technologies), mobile phase: 50:50 water:acetonitrile with $0.01 \mathrm{wt} \%$ trifluoracetic acid). A calibration curve of absorbance against $\mathrm{MB}$ concentrations was obtained by using MB solutions of known concentrations (Fig. S1, ESI $\dagger$ ).

Carbohydrate-binding module (CBM) depletion isotherms were constructed by incubating a $78.5 \mathrm{~mm}^{2}$ piece of the produced cellulose hydrogels with various concentrations (6.25-200 $\mu \mathrm{M})$ of ThCBM $_{\mathrm{CBHI}}$ in $100 \mu \mathrm{L}$ of $50 \mathrm{mM}$ PBS pH 7.0. Controls without cellulose were included and all experiments were conducted in triplicate. Samples were incubated at $4{ }^{\circ} \mathrm{C}$ for $24 \mathrm{~h}$ with agitation (roller table); $2 \mu \mathrm{L}$ of the supernatant were removed and the concentration of free protein calculated by the absorbance measured at $280 \mathrm{~nm}$ using a NanoDrop 2000 Spectrophotometer (Thermos Fisher Scientific). The concentration of the bound $T h \mathrm{CBM}_{\mathrm{CBHI}}$ was calculated from the difference in initial and final $T h \mathrm{CBM}_{\mathrm{CBHI}}$ concentration in the supernatant.

Partition constants were obtained from the depletion isotherms (plot of final concentration versus mass of molecular probe adsorbed per gram of cellulose) after fitting of the raw data to a Langmuir-type adsorption model:

$$
Y=\frac{N}{N_{\mathrm{m}}}=\frac{K C}{1+K C}
$$

where $Y$ is the fraction of the surface covered by the adsorbed molecular probe, $N$ is the number of moles of the molecular probe adsorbed per gram of cellulose at the equilibrium concentration $\left(\mu \mathrm{mol} \mathrm{g}{ }^{-1}\right), N_{\mathrm{m}}$ is the number of moles of the molecular probe per gram of cellulose required to form a monolayer $\left(\mu \mathrm{mol} \mathrm{g}^{-1}\right), K$ is the equilibrium association constant $\left(\mu \mathrm{M}^{-1}\right)$, and $C$ is the molecular probe concentration at equilibrium $(\mu \mathrm{M})$.

Rearrangement of the equation enabled calculation of $N_{\mathrm{m}}$ and $K$ (Table S4, ESI $\dagger$ ) for the molecular probes by plotting $C / N$ versus $C$ (Fig. $\mathrm{S} 2$ and $\mathrm{S} 3, \mathrm{ESI} \dagger)$ :

$$
\frac{C}{N}=\frac{C}{N_{\mathrm{m}}}+\frac{1}{K N_{\mathrm{m}}}
$$

enabling the specific surface area, and the partition constant (initial gradient of the fitted isotherm) to be calculated for each hydrogel:

$$
S=N_{\mathrm{m}} a N_{\mathrm{Av}}
$$

where $S$ is the specific surface area accessible to the probe molecule, $a$ is the occupied surface area of the probe molecule, and $N_{\mathrm{Av}}$ is Avogadro's number.

\section{Confocal microscopy bleaching}

The cysteine residue inserted into $T h \mathrm{CBM} 1_{\mathrm{CBHI}}$ by mutation was specifically labelled with Alexa Fluor 488 C5 Maleimide (Invitrogen) dye, following the manufacturer's instructions. Briefly, $100 \mu \mathrm{M}$ of $T h \mathrm{CBM} 1_{\mathrm{CBHI}}+$ SUMO in $50 \mathrm{mM}$ phosphate buffer, pH 7.0, was incubated with excess dye 1 :10 mole ratio of protein : dye) overnight at $10{ }^{\circ} \mathrm{C}$. Size exclusion chromatography was used to remove excess dye from the labelled protein: the sample was passed through a GE Superdex 75 10/300 GL column, connected to a GE Healthcare ÄKTAprime system, preequilibrated with $50 \mathrm{mM}$ phosphate buffer, $\mathrm{pH}$ 7.0, and $150 \mathrm{mM}$ NaCl. Fractions collected as the labelled protein eluted were combined and the concentration of labelled protein, and the degree of labelling, were estimated by absorbance measurements at $280 \mathrm{~nm}$ and $494 \mathrm{~nm}$ (dye absorbance maximum) using a NanoDrop 2000 Spectrophotometer (Thermos Fisher Scientific).

Cellulose hydrogel samples, $134.2 \mathrm{~mm}^{2}$, were incubated with fluorescein-modified $T h \mathrm{CBM}_{\mathrm{CBHI}}$ at a concentration of $10 \mathrm{nM}$ for $19 \mathrm{~h}$ at $16{ }^{\circ} \mathrm{C}$. The samples were then washed twice with PBS before being analysed using a Zeiss LSM 780 confocal microscope. Images were taken using a $405 \mathrm{~nm}$ diode laser at $17 \%$ power output, an excitation wavelength of $488 \mathrm{~nm}$ and absorption wavelength of $525 \mathrm{~nm}$. An area of the sample was selectively bleached by multiple passes of the laser operating at $100 \%$ power until the fluorescence intensity of the area had halved (Fig. S5, ESI $\dagger$ ). Images of the sample were then taken every minute for $1 \mathrm{~h}$ to measure recovery.

Theoretical fluorescence recovery curves based on the equation developed by Axelrod et al. ${ }^{41}$ were applied to the raw data in order to calculate the maximum fluorescence intensity recovery and the recovery half-life, i.e. the time required for the intensity of the bleached area to recover its intensity to half that of the final intensity value:

$$
Z_{t}=\frac{I_{t}}{I_{\max }}=1-\frac{k}{2\left(1+\frac{t}{\tau_{\mathrm{D}}}\right)}
$$

where $Z_{t}$ is the fraction of maximum recoverable intensity recovered at time $t, I_{t}$ is the fluorescence intensity at time $t$, $I_{\max }$ is the maximum recoverable fluorescence intensity, $k$ is a constant, and $\tau_{\mathrm{D}}$ is the characteristic diffusion time. The diffusion coefficient, $D$, is related to $\tau_{\mathrm{D}}$ and the half-width of the bleached profile, $\omega$ :

$$
D=\frac{\omega^{2}}{4 \tau_{\mathrm{D}}}
$$

\section{Results and discussion}

The dissolution and regeneration of cellulose results in highly porous hydrogels that contain very little cellulosic material (Table 1); densities were ca. $20 \mathrm{~kg} \mathrm{~m}^{-3}$ compared to the absolute density of pure cellulose of $1592 \mathrm{~kg} \mathrm{~m}^{-3} \cdot{ }^{42}$ Analysis of pXRD patterns revealed that both cellulose and anti-solvent type affect the overall crystallinity of the regenerated hydrogel (Fig. 1). Both untreated BC and AC are type I cellulose, indicated by pXRD peaks around $2 \theta=14.8,16.8,22.0$ and $22.5^{\circ}$, whilst all the regenerated samples are type II, indicated by peaks around $2 \theta=12.1,13.0,19.8$ and $20.6^{\circ} \cdot{ }^{4-45}$ Dissolution and regeneration of cellulose resulted in hydrogels with reduced crystallinity compared to the starting materials - the crystallinity indices for untreated $\mathrm{BC}$ and $\mathrm{AC}$ were 0.88 and 0.45 respectively (Table 1). Regeneration in water resulted in a 
Table 1 Effects of choice of cellulose starting material and anti-solvent on regenerated cellulose hydrogel density, porosity, crystallinity, modal nanopore diameter, median micropore diameter, and nano: micro pore ratio

\begin{tabular}{lllllll}
\hline Sample & $\begin{array}{l}\text { Density } \\
{\left[\mathrm{kg} \mathrm{m}^{-3}\right]}\end{array}$ & $\begin{array}{l}\text { Porosity } \\
{[\%]}\end{array}$ & $\begin{array}{l}\text { Crystallinity } \\
\text { index }\end{array}$ & $\begin{array}{l}\text { Modal nanopore } \\
\text { diameter }^{a}[\mathrm{~nm}]\end{array}$ & $\begin{array}{l}\text { Median micropore } \\
\text { diameter }^{b}\left[\mathrm{~nm}^{-3}\right.\end{array}$ & $\begin{array}{l}\text { Nano: micro } \\
\text { pore ratio }^{c}\end{array}$ \\
\hline ACrM & $17 \pm 1$ & 99 & 0.18 & 50 & 226 \\
ACrW & $22 \pm 2$ & 99 & 0.27 & 36 & 224 & $10: 1$ \\
BCrM & $18 \pm 1$ & 99 & 0.19 & 54 & 190 & $12: 1$ \\
BCrW & $17 \pm 1$ & 99 & 0.32 & 44 & 206 & $6: 1$
\end{tabular}

${ }^{a}$ Determined from NMR cryoporometry. ${ }^{b}$ Determined from SEM micrographs. ${ }^{c}$ Determined from NMR relaxometry studies.
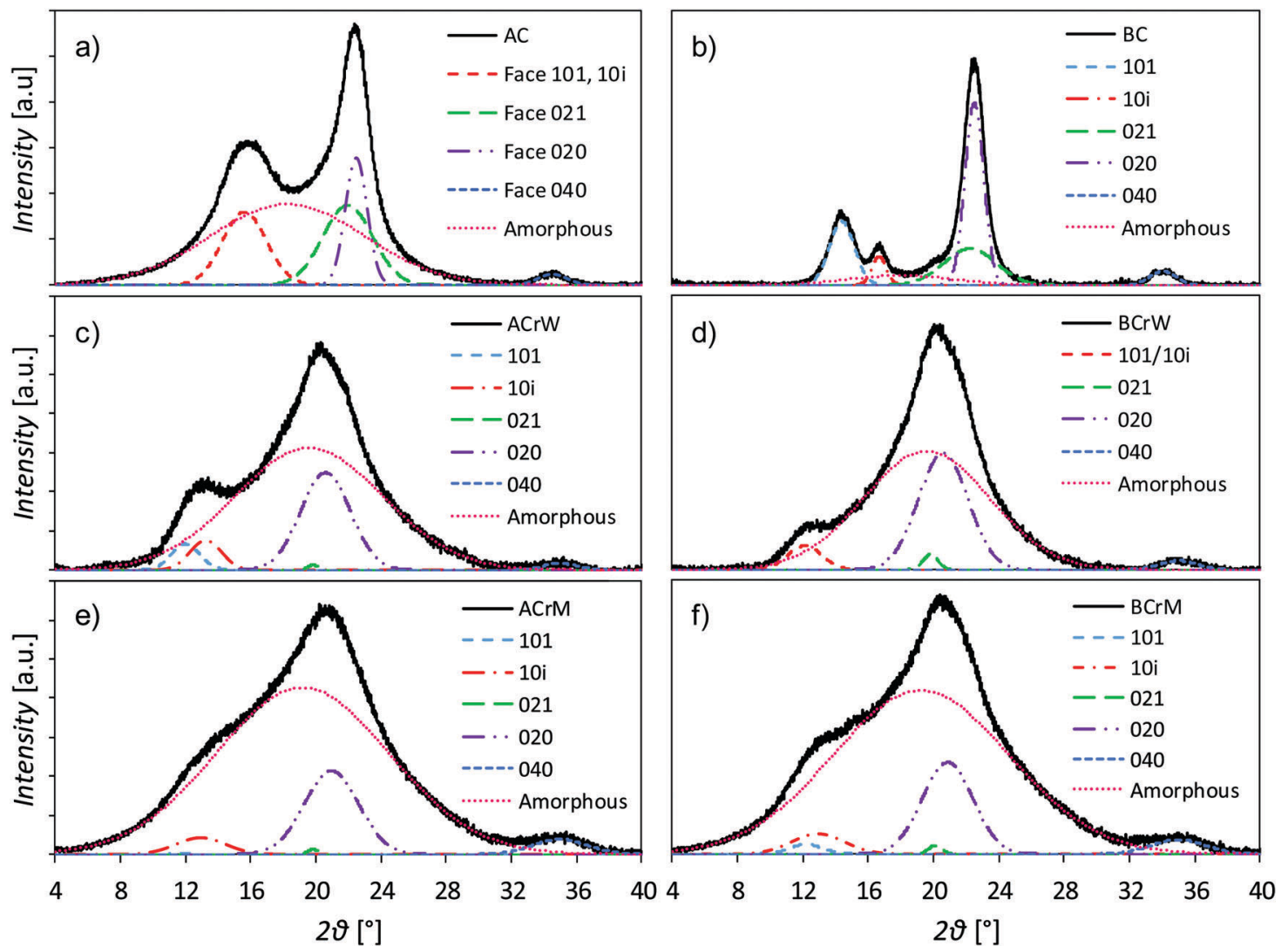

Fig. 1 pXRD patterns of samples with crystalline and amorphous peaks fitted: (a) unprocessed $\alpha$-cellulose (AC); (b) unprocessed bacterial cellulose (BC); (c) $\alpha$-cellulose regenerated in water (ACrW); (d) bacterial cellulose regenerated in water (BCrW); (e) $\alpha$-cellulose regenerated in methanol (ACrM); and (f) bacterial cellulose regenerated in methanol (BCrM). Dissolution and regeneration of cellulose results in type II crystalline material with more amorphous material formed after regeneration using methanol compared to water.

higher degree of crystallinity than regeneration in methanol for both cellulose types with an average increase of $59 \%$.

To probe the pore structure of the hydrogels without drying, two NMR techniques were employed: relaxometry and cryoporometry. In the former the dependence of proton transverse relaxation time $\left(T_{2}\right)$ and surface to volume ratio of pores was exploited. To complement this, and overcome difficulties in defining pore diameters, ${ }^{38}$ cryoporometry was used to probe specific pore size $(<100 \mathrm{~nm}) .{ }^{46,47}$

The ILT of the CPMG decays obtained for the hydrogels revealed a $T_{2}$ distribution profile with three distinct peaks. The peak at the highest $T_{2}$ value is ascribed to the bulk water in the PBS, which is justified by the comparison with the $T_{2}$ distribution profile obtained for the pure solution (Fig. 2C, inset).
The absence of a precise value for the relaxivity constant of water (PBS) inside cellulose pores frustrates association of $T_{2}$ distributions with specific pore diameters. However, based on previously published data $^{48}$ and on the averaged $T_{2}$ values reported for pure water filling pores of known dimensions in cellulose ${ }^{49-52}$ the relaxivity of pure water inside cellulose pores can be estimated to be in the range $10^{-6}-10^{-7} \mathrm{~nm} \mathrm{~s}{ }^{-1}$. Thus, using the relation between pore dimension $T_{2}$ and relaxivity constant previously reported, ${ }^{48}$ the $T_{2}$ range from $10-100 \mathrm{~ms}$ was ascribed to pores with dimensions in the range 10-100 nm and the $T_{2}$ range from $100 \mathrm{~ms}$ to $1 \mathrm{~s}$ to pores with dimensions in the range $100 \mathrm{~nm}$ to a few $\mu \mathrm{m}$. Thus, in Fig. $2 \mathrm{C}$, the peaks at the shorter $T_{2}$ values reflect nanopores, while the peaks with intermediate $T_{2}$ reflect micropores. The peak corresponding to 

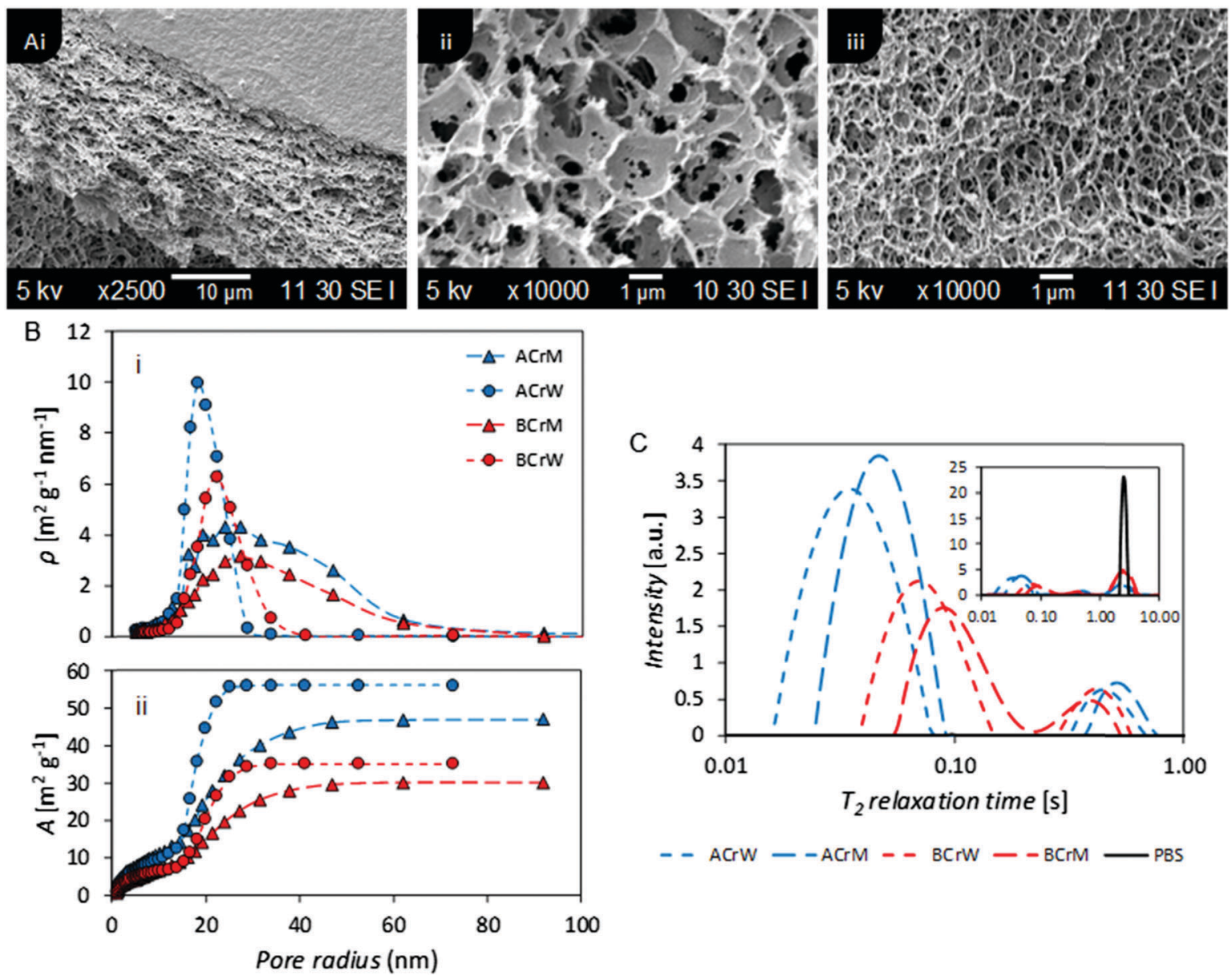

- - ACrW - - ACrM - - BCrW - $-\mathrm{BCrM}-\mathrm{PBS}$

Pore radius $(\mathrm{nm})$

Fig. 2 (A) (i) SEM micrograph of a lyophilised cellulose hydrogel showing the porous structure below a dense skin layer - all hydrogels exhibited this bulk structure, (ii) and (iii) SEM micrographs of ACrM and BCrW samples showing differences in micropore size. (B) Nanometer pore size distribution of hydrogels based on NMR cryoporometry: (i) specific pore surface area density ( $\rho$ ), and (ii) specific cumulative pore surface area. Both choice of cellulose and anti-solvent have an effect on the overall pore structure of the hydrogels in agreement with relaxometry studies. (C) NMR $T_{2}$ relaxation distribution curves for regenerated cellulose hydrogels providing relative surface areas for nano- and micropores. Both choice of cellulose and anti-solvent have an effect on the overall pore structure of the hydrogels. Bulk PBS measurement included in inset.

nanopores for $\mathrm{AC}$ reflected a smaller median pore diameter than that for BC, whilst hydrogels regenerated in methanol exhibited larger pores than those regenerated in water. NMR cryoporometry confirmed these observations, yielding a modal pore diameter of $36 \mathrm{~nm}$ for AC regenerated in water and $54 \mathrm{~nm}$ for $\mathrm{BC}$ regenerated in methanol (Fig. $2 \mathrm{~B}$ and Table 1). It is of interest to note that Östlund et al. reported a pore radius distribution between $2-15 \mathrm{~nm}$, based on NMR cryoporometry for cellulose samples regenerated from [EMIm] [OAc] only, ${ }^{10}$ whilst the distribution in these hydrogels is between $10-70 \mathrm{~nm}$, suggesting that the ratio of ionic liquid to co-solvent in the organic electrolyte solution used could influence the pore size of the resultant regenerated hydrogels, providing further opportunities to tune porosity.

NMR relaxometry studies revealed that micropores (above the range that can be probed with NMR cryoporometry) in AC exhibited a slightly larger median diameter than those in BC, as confirmed by analysis of SEM micrographs (Fig. 2A and Table 1). Significantly more nanopores were present in AC, as reflected in the ratio between the integrated nano- and micropore peak areas in the relaxometry data: that of $\mathrm{AC}$ was double that of BC (Table 1). In both cases, hydrogels regenerated in water show a $20 \%$ increase in nano- to micropore ratio versus those regenerated in methanol. To validate these results, and to discern whether such differences were important at a molecular scale, passive MB adsorption (used to characterize cotton fibers) ${ }^{53}$ was conducted. This enabled calculation of the cellulose surface area in the never-dried hydrogels, whilst providing a molecular probe small enough to access pores inaccessible to the larger CBM. (MB has an occupied surface area of $197.2 \AA^{2}$ whilst $T h \mathrm{CBM}_{\mathrm{CBHI}}$ has a maximum occupied area of approximately $985 \AA^{2}$, assuming a globular structure. ${ }^{54,55}$ )

MB adsorption isotherms (Fig. 3a) revealed that BCrM had a lower surface area than ACrW (Table 2), in accordance with the observation that ACrW has a higher population of nanopores with smaller diameters (Table 1). The choice of cellulose influences the surface area by a factor of $1.6\left(\operatorname{total}_{\mathrm{AC}} / \mathrm{total}_{\mathrm{BC}}\right)$, 

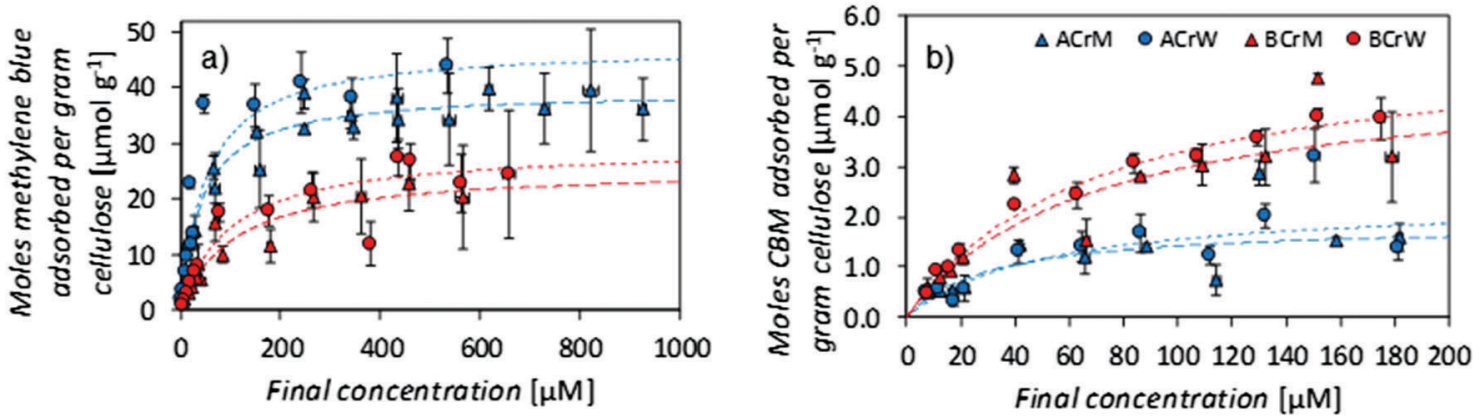

Fig. 3 (a) Methylene blue adsorption isotherms on regenerated cellulose scaffolds, (b) ThCBM ${ }_{\mathrm{CBH}}$ adsorption isotherms on regenerated cellulose scaffolds. Error bars \pm 1 standard error. Whilst a greater surface area is accessible to methylene blue in $\alpha$-cellulose samples, a greater area is accessible to ThCBM ${ }_{\mathrm{CBH}}$ in bacterial cellulose samples. Water regenerated samples have a greater accessible area in all cases.

Table 2 Specific surface area and partition constants per unit mass and per unit area for methylene blue (MB) and ThCBMCBHI adsorption on regenerated cellulose hydrogels

\begin{tabular}{|c|c|c|c|c|c|c|}
\hline Sample & $\begin{array}{l}\text { MB specific } \\
\text { surface area } \\
{\left[\mathrm{m}^{2} \mathrm{~g}^{-1}\right]}\end{array}$ & $\begin{array}{l}\text { MB partition } \\
\text { constant } \\
{\left[\times 10^{-3} \mathrm{~L} \mathrm{~g}^{-1}\right]}\end{array}$ & $\begin{array}{l}\text { MB partition } \\
\text { constant } \\
{\left[\times 10^{-3} \mathrm{~L} \mathrm{~m}^{-2}\right]}\end{array}$ & $\begin{array}{l}\text { CBM specific } \\
\text { surface area } \\
{\left[\mathrm{m}^{2} \mathrm{~g}^{-1}\right]}\end{array}$ & $\begin{array}{l}\text { CBM partition } \\
\text { constant } \\
{\left[\times 10^{-3} \mathrm{~L} \mathrm{~g}^{-1}\right]}\end{array}$ & $\begin{array}{l}\text { CBM partition } \\
\text { constant } \\
{\left[\times 10^{-3} \mathrm{~L} \mathrm{~m}^{-2}\right]}\end{array}$ \\
\hline ACrM & 47 & 855 & 18.3 & 14 & 53 & 3.8 \\
\hline BCrM & 30 & 288 & 9.5 & 29 & 70 & 2.4 \\
\hline BCrW & 35 & 236 & 6.8 & 33 & 76 & 2.3 \\
\hline
\end{tabular}

whilst the choice of anti-solvent affects the surface area by a factor of 1.2 (total $_{\mathrm{rW}} /$ total $_{\mathrm{rM}}$ ).

The surface area available for CBM attachment was also affected by the cellulose and anti-solvent type: rW hydrogels had a 1.2 increase in the $T h \mathrm{CBM}_{\mathrm{CBHI}}$ accessible surface area, due either to the higher proportion of nanopores with smaller diameters, or to the increase in crystallinity, compared to rM hydrogels. However, the use of AC resulted in a reduction of the surface area accessible to $T h \mathrm{CBM}_{\mathrm{CBHI}}$ by a factor of 0.4 . It is hypothesised that a significant proportion of the pores in the AC samples accessible to $\mathrm{MB}$ are inaccessible to $T h \mathrm{CBM}_{\mathrm{CBHI}}$ (due to its larger size). Of the pore surface accessible to $\mathrm{MB}$, 95\% is accessible to $T h \mathrm{CBM}_{\mathrm{CBHI}}$ in hydrogels prepared from $\mathrm{BC}$, whilst only $24 \%$ is accessible in hydrogels prepared from AC. This is supported by the nanopore:micropore ratios derived from the NMR relaxometry experiments (Table 1 ).

It is apparent that both the cellulose type (differing by DP only) and anti-solvent identity influenced the partition constants of MB (Table 2). MB partition constants measured for AC derived hydrogels are higher than for BC derived hydrogels and this may reflect differences in processing of the raw materials used. 9 CBM partition constants expressed in units of $\mathrm{L} \mathrm{m}^{-2}$ (which more accurately reflects the surfaces available for adsorption of the probe molecules) gave distinctly larger values for rM samples versus rW samples when MB was used as the probe molecule. It has been reported that the partition constant for monosaccharide adsorption increased with the hydrophobicity

T AC materials may be subjected to an acid wash during purification potentially leading to introduction of a very small number of acid groups on the surfaces that would bind a positively charged probe, such as MB, strongly. index of the monosaccharide. ${ }^{56}$ Considering this to reflect in the reverse, i.e. adsorption onto polysaccharide surfaces, this might suggest greater hydrophobicity of surfaces in rM samples versus rW samples. This reflects previously published data pertaining to crystallinity: Östlund et al. argued that faster rates of demixing in water 'trap' the methylhydroxyl groups in the gauche-trans formation that is found in cellulose II. $^{10}$ This results in a higher crystallinity for samples regenerated in water than those regenerated in methanol, where the methylhydroxyl groups adopt the more energetically favourable gauche-gauche confirmation, demonstrated computationally by Liu et al. ${ }^{57}$ If samples regenerated in methanol are more hydrophobic - due either to the conformation of the methylhydroxyl groups, or to the specific crystalline faces exposed this would account for the observed difference. No such differences are noted in binding of $T h \mathrm{CBM}_{\mathrm{CBHI}}$, with partition constants ranging between 3.8 and $2.3 \mathrm{~mL} \mathrm{~m}^{-2}$, reflecting the inaccessibility of the smaller pores to the large biomolecule (Table 2).

It is also of note that the partition constants expressed per unit mass, reported here for a family $1 \mathrm{CBM}$, are two orders of magnitude lower than those reported previously: a partition constant of $1.0 \times 10^{5} \mathrm{M}^{-1}$ was reported for $T$. reesei $\mathrm{CBM}_{\mathrm{CBHI}}$ on native $\mathrm{BC},{ }^{25}$ and $4.9 \mathrm{~L} \mathrm{~g}^{-1}$ on microcrystalline cellulose; ${ }^{58}$ compared to $1.5 \times 10^{3} \mathrm{M}^{-1}$ and $7.6 \times 10^{-2} \mathrm{~L} \mathrm{~g}^{-1}$ on BCrW in this work. This reflects the lower degree of crystallinity in these regenerated samples, although, as previously discussed in the literature, these values do not take into account the accessible surface area. ${ }^{59}$

To test the hypothesis that some pores are inaccessible to CBMs, the rates of diffusion of fluorescently tagged $T h \mathrm{CBM}_{\mathrm{CBHI}}$ in hydrogels were determined from rates of recovery of fluorescent intensity after bleaching, using confocal microscopy. Recovery of the fluorescence intensity after bleaching is observed (Fig. 4), 


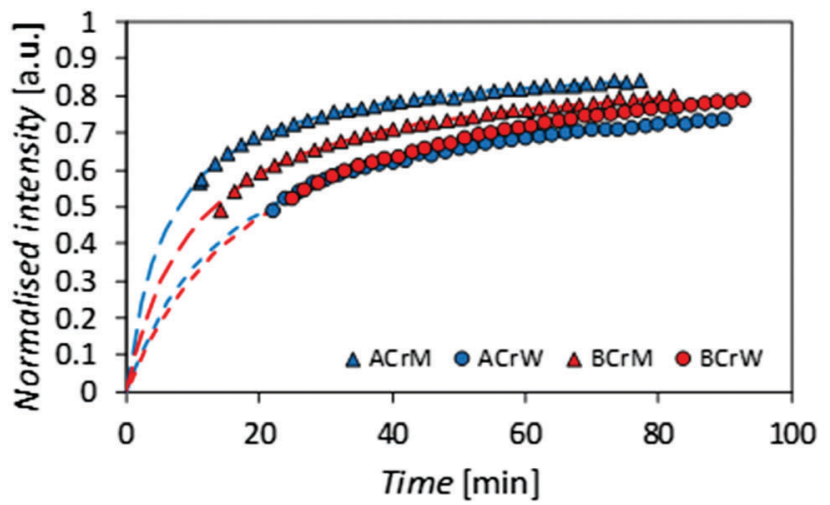

Fig. 4 Recovery of fluorescence intensity for regenerated cellulose hydrogels after bleaching. A more rapid recovery is observed in the methanol regenerated samples and those generated from $\alpha$-cellulose.

Table 3 Maximum recoverable fluorescence intensity, $I_{\max }$ curve constant, $k$, characteristic diffusion time, $\tau_{\mathrm{D}}$, recovery half-life, $t_{1 / 2}$, and ThCBM ${ }_{\mathrm{CBHI}}$ diffusion coefficient, $D$, for hydrogels based on bleaching studies

\begin{tabular}{lllccl}
\hline Sample & $I_{\max }$ & $k\left[\mathrm{~min}^{-1}\right]$ & $\tau_{\mathrm{D}}[\mathrm{min}]$ & $t_{1 / 2}[\mathrm{~min}]$ & $D\left[\mu \mathrm{m}^{2} \mathrm{~min}^{-1}\right]$ \\
\hline ACrM & 0.91 & 2.00 & 6.3 & 7.8 & 1.76 \\
ACrW & 0.86 & 2.01 & 15.3 & 21.6 & 0.73 \\
BCrM & 0.90 & 2.00 & 10.4 & 13.2 & 1.07 \\
BCrW & 0.96 & 2.01 & 20.3 & 22.5 & 0.55
\end{tabular}

confirming that $T h \mathrm{CBM}_{\mathrm{CBHI}}$ is reversibly bound to the cellulose, in agreement with previous reports. ${ }^{25}$ The differences in the recovery half-lives and subsequent diffusion coefficients of the samples can be attributed to three different effects: (i) the pore structure of the hydrogels - a structure with fewer pores accessible to the CBM is more tortuous, resulting in a lower CBM diffusion rate and thus a longer recovery period; (ii) the affinity of the CBM to the cellulose, a higher partition constant resulting in a higher diffusion rate; and (iii) the hydrophobicity of the sample - it has been reported, based on computational simulations, that CBM could diffuse from hydrophilic to hydrophobic surfaces, but that the reverse transition was not observed in $43 \mathrm{~ms}$ of simulation, ${ }^{27}$ suggesting that a slower diffusion rate would be observed along surfaces with more hydrophilic character.

Given that the diffusion coefficient increases by a factor of 1.5 for AC compared to BC (Table 3), it is apparent that the affinity of the CBM for the cellulose surfaces is more important than the hydrogel tortuosity (assumed to be proportional to the difference in accessible surface area for $T h \mathrm{CBM}_{\mathrm{CBHI}}$ compared to $\mathrm{MB}$ ). With regards to the anti-solvent type, rM hydrogels increase the diffusion coefficient by a factor of 2.2 over rW hydrogels. In this instance, the tortuosity and presumed hydrophobicity of the hydrogel are more important than the CBM affinity.

\section{Conclusions}

Cellulose hydrogels regenerated from solutions containing ionic liquids have been used in a plethora of applications, but, in many cases, the materials have primarily been characterised using techniques requiring drying. Here, careful "wet" characterisation of never-dried cellulose hydrogels has revealed that subtle changes in choice of raw material and regeneration solvents can result in significant differences in the hydrogel products. This has wide ramifications for many cellulose hydrogel and material applications.

Specifically, the choice of cellulose starting material (with different DP) and anti-solvent used in generating cellulose hydrogels from solutions containing ionic liquids influence the crystallinity and pore structure of the resulting hydrogel. In turn, these affect the tortuosity and hydrophobicity of the porous material and, thus, the affinity of molecules adsorbing onto and migrating through, the hydrogel. Small molecules, such as the widely used probe methylene blue, do not yield information that can be extrapolated to larger probes, such as proteins, including CBMs. It is also clear that compromises may need to be made between the maximum accessible surface area for the CBM, here $33 \mathrm{~m}^{2} \mathrm{~g}^{-1}$ for bacterial cellulose regenerated in water, and maximum CBM partition constant per unit area and CBM diffusion coefficient, here $3.8 \mathrm{~mL} \mathrm{~m}^{-2}$ and $1.76 \mu \mathrm{m}^{2} \min ^{-1}$ for $\alpha$-cellulose regenerated in methanol. Thus, cellulose hydrogels optimized for various CBM-based bioaffinity applications may be prepared by manipulating the cellulose DP and anti-solvent. For example, the use of methanol to regenerate the hydrogel will lead to a higher enzymatic hydrolysis rate due to the increased CBM migration rate. In addition, bacterial cellulose has been widely posited as a biocompatible material and many potential applications of such hydrogels will rely on hydrogel structure.

\section{Conflict of interest}

There are no conflicts of interest to declare.

\section{Acknowledgements}

The authors acknowledge the following funding: $\mathrm{PhD}$ studentship funding for M. A. J. from the UK Engineering and Physical Sciences Research Council (EPSRC) via the EPSRC Doctoral Training Centre in Sustainable Chemical Technologies, University of Bath (EP/G03768X/1); the São Paulo State Research Foundation (FAPESP) (grant 09/52840-7); the Brazilian National Council for Scientific and Technological Research (CNPq) (grants 490022/ 2009-0 and 312852/2014-2); and the British Council via the Global Innovation Initiative programme, which facilitated UK/Brazilian collaboration. All data are available from the University of Bath data archive at http://doi.org/10.15125/BATH-00316.

\section{Notes and references}

1 D. Klemm, B. Heublein, H.-P. Fink and A. Bohn, Angew. Chem., Int. Ed., 2005, 44, 3358-3393.

2 J. C. Courtenay, M. A. Johns, F. Galembeck, C. Deneke, E. M. Lanzoni, C. A. Costa, J. L. Scott and R. I. Sharma, Cellulose, 2017, 24, 253-267. 
3 A. Sydney Gladman, E. A. Matsumoto, R. G. Nuzzo, L. Mahadevan and J. A. Lewis, Nat. Mater., 2016, 15, 413-418.

4 B. D. B. Aaronson, D. He, E. Madrid, M. A. Johns, J. L. Scott, L. Fan, J. Doughty, M. A. S. Kadowaki, I. Polikarpov, N. B. McKeown and F. Marken, ChemistrySelect, 2017, 2, 871-875.

5 C. B. Field, M. J. Behrenfeld, J. T. Randerson and P. Falkowski, Science, 1998, 281, 237-240.

6 R. P. Swatloski, S. K. Spear, J. D. Holbrey and R. D. Rogers, J. Am. Chem. Soc., 2002, 124, 4974-4975.

7 J.-I. Kadokawa, M.-A. Murakami and Y. Kaneko, Carbohydr. Res., 2008, 343, 769-772.

8 O. Aaltonen and O. Jauhiainen, Carbohydr. Polym., 2009, 75, 125-129.

9 R. Rinaldi, Chem. Commun., 2011, 47, 511-513.

10 Å. Östlund, A. Idström, C. Olsson, P. Larsson and L. Nordstierna, Cellulose, 2013, 20, 1657-1667.

11 X. Geng and W. A. Henderson, RSC Adv., 2014, 4, 31226-31229.

12 A. B. Boraston, D. N. Bolam, H. J. Gilbert and G. J. Davies, Biochem. J., 2004, 382, 769-781.

13 M. A. Goldstein, M. Takagi, S. Hashida, O. Shoseyov, R. H. Doi and I. H. Segel, J. Bacteriol., 1993, 175, 5762-5768.

14 J. Credou and T. Berthelot, J. Mater. Chem. B, 2014, 2, 4767-4788.

15 Z. Xu, W. Bae, A. Mulchandani, R. K. Mehra and W. Chen, Biomacromolecules, 2002, 3, 462-465.

16 A. Fishman, I. Levy, U. Cogan and O. Shoseyov, J. Mol. Catal. B: Enzym., 2002, 18, 121-131.

17 S. Hwang, J. Ahn, S. Lee, T. Lee, S. Haam, K. Lee, I.-S. Ahn and J.-K. Jung, Biotechnol. Lett., 2004, 26, 603-605.

18 H. Park, J. Ahn, J. Lee, H. Lee, C. Kim, J.-K. Jung, H. Lee and E. G. Lee, Int. J. Mol. Sci., 2012, 13, 358-368.

19 W. Lewis, E. Keshavarz-Moore, J. Windust, D. Bushell and N. Parry, Biotechnol. Bioeng., 2006, 94, 625-632.

20 Y. Cao, Q. Zhang, C. Wang, Y. Zhu and G. Bai, J. Chromatogr. A, 2007, 1149, 228-235.

21 A. Karpol, L. Kantorovich, A. Demishtein, Y. Barak, E. Morag, R. Lamed and E. A. Bayer, J. Mol. Recognit., 2009, 22, 91-98.

22 A. Wierzba, U. Reichl, R. F. B. Turner, R. A. J. Warren and D. G. Kilburn, Biotechnol. Bioeng., 1995, 46, 185-193.

23 F. K. Andrade, S. M. G. Moreira, L. Domingues and F. M. P. Gama, J. Biomed. Mater. Res., Part A, 2010, 92, 9-17.

24 R. Pértile, S. Moreira, F. Andrade, L. Domingues and M. Gama, Biotechnol. Prog., 2012, 28, 526-532.

25 P. Tomme, A. Boraston, B. McLean, J. Kormos, A. L. Creagh, K. Sturch, N. R. Gilkes, C. A. Haynes, R. A. J. Warren and D. G. Kilburn, J. Chromatogr. B: Biomed. Sci. Appl., 1998, 715, 283-296.

26 J. Lehtiö, J. Sugiyama, M. Gustavsson, L. Fransson, M. Linder and T. T. Teeri, Proc. Natl. Acad. Sci. U. S. A., 2003, 100, 484-489.

27 M. R. Nimlos, G. T. Beckham, J. F. Matthews, L. Bu, M. E. Himmel and M. F. Crowley, J. Biol. Chem., 2012, 287, 20603-20612.

28 K. B. Pal, H. Chatterjee and P. B. Sarkar, Nature, 1952, 169, 845-846.

29 É. Pecoraro, D. Manzani, Y. Messaddeq and S. J. L. Ribeiro, in Monomers, Polymers and Composites from Renewable Resources, ed. M. N. Belgacem and A. Gandini, Elsevier,
Amsterdam, 2007, ch. 17, pp. 369-383, DOI: 10.1016/B978-008-045316-3.00017-X.

30 M. Schramm and S. Hestrin, Microbiology, 1954, 11, 123-129. 31 B. L. Mello and I. Polikarpov, AMB Express, 2014, 4, 1-6.

32 E. Mossessova and C. D. Lima, Mol. Cell, 2000, 5, 865-876.

33 M. Wojdyr, J. Appl. Crystallogr., 2010, 43, 1126-1128.

34 S. Berger and S. Braun, 200 and More NMR Experiments, Wiley-VCH, Weinheim, Germany, 2004.

35 H. Y. Carr and E. M. Purcell, Phys. Rev., 1954, 94, 630-638.

36 S. Meiboom and D. Gill, Rev. Sci. Instrum., 1958, 29, 688-691.

37 K. R. Brownstein and C. E. Tarr, Phys. Rev. A: At., Mol., Opt. Phys., 1979, 19, 2446-2453.

38 J. Mitchell, S. C. Stark and J. H. Strange, J. Phys. D: Appl. Phys., 2005, 38, 1950-1958.

39 S. W. Provencher, Comput. Phys. Commun., 1982, 27, 229-242.

40 G. C. Borgia, R. J. S. Brown and P. Fantazzini, J. Magn. Reson., 1998, 132, 65-77.

41 D. Axelrod, D. E. Koppel, J. Schlessinger, E. Elson and W. W. Webb, Biophys. J., 1976, 16, 1055-1069.

42 L. Y. Mwaikambo and M. P. Ansell, J. Mater. Sci. Lett., 2001, 20, 2095-2096.

43 M. Ago, T. Endo and T. Hirotsu, Cellulose, 2004, 11, 163-167. 44 S. Park, J. O. Baker, M. E. Himmel, P. A. Parilla and D. K. Johnson, Biotechnol. Biofuels, 2010, 3, 10.

45 N. Terinte, R. Ibbett and K. C. Schuster, Lenzinger Ber., 2011, 89, 118-131.

46 O. V. Petrov and I. Furó, Prog. Nucl. Magn. Reson. Spectrosc., 2009, 54, 97-122.

47 E. Shiko, K. J. Edler, J. P. Lowe and S. P. Rigby, J. Colloid Interface Sci., 2012, 385, 183-192.

48 C. Zhang, P. Li, Y. Zhang, F. Lu, W. Li, H. Kang, J.-F. Xiang, Y. Huang and R. Liu, Polymer, 2016, 98, 237-243.

49 D. Capitani, N. Proietti, F. Ziarelli and A. L. Segre, Macromolecules, 2002, 35, 5536-5543.

50 N. Proietti, D. Capitani, E. Pedemonte, B. Blümich and A. L. Segre, J. Magn. Reson., 2004, 170, 113-120.

51 C. Felby, L. G. Thygesen, J. B. Kristensen, H. Jørgensen and T. Elder, Cellulose, 2008, 15, 703-710.

52 J. E. Tsuchida, C. A. Rezende, R. de Oliveira-Silva, M. A. Lima, M. N. d'Eurydice, I. Polikarpov and T. J. Bonagamba, Biotechnol. Biofuels, 2014, 7, 127.

53 C. Kaewprasit, E. Hequet, N. Abidi and J. Paul, J. Cotton Sci., 1998, 2, 164-173.

54 D. Graham, J. Phys. Chem., 1955, 59, 896-900.

55 H. P. Erickson, Biol. Proced. Online, 2009, 11, 32-51.

56 K. Miyajima, K. Machida, T. Taga, H. Komatsu and M. Nakagaki, J. Chem. Soc., Faraday Trans. 1, 1988, 84, 2537-2544.

57 H. Liu, G. Cheng, M. Kent, V. Stavila, B. A. Simmons, K. L. Sale and S. Singh, J. Phys. Chem. B, 2012, 116, 8131-8138.

58 M. Linder and T. T. Teeri, Proc. Natl. Acad. Sci. U. S. A., 1996, 93, 12251-12255.

59 R. Pinto, S. Moreira, M. Mota and M. Gama, Langmuir, 2004, 20, 1409-1413.

60 O. N. Reva, I. E. Zaets, L. P. Ovcharenko, O. E. Kukharenko, S. P. Shpylova, O. V. Podolich, J.-P. de Vera and N. O. Kozyrovska, AMB Express, 2015, 5, 35, DOI: 10.1186/s13568-015-0124-5. 